\title{
Classes de cobertura vegetal no município de Taperoá, Paraíba
}

O município de Taperoá localiza-se na região central do Estado da Paraíba, Mesorregião Borborema e Microrregião do Cariri Ocidental. O município está incluído na área geográfica de abrangência do semiárido do Brasil, tendo como critérios o índice pluviométrico, o índice de aridez e o risco a seca. Esta pesquisa está centrada no estudo da degradação ambiental no município de Taperoá - Paraíba, levando em consideração os limites geográficos que fica em torno da sub-bacia do rio, sendo ao norte, Areia de Baraúna, Salgadinho e Assunção, ao leste, Santo André e São José dos Cordeiros, ao sul, São José dos Cordeiros e Livramento, e ao oeste, Cacimbas e Passagem. Foram utilizados recursos disponíveis através das técnicas de geoprocessamento. $O$ objetivo geral da pesquisa é analisar os níveis de degradação a partir de um estudo espaço temporal da cobertura vegetal, degradação das terras, além das vulnerabilidades da região, sendo elas social, econômica, tecnológica, ambiental e de susceptibilidade as estiagens. Para atender tais objetivos, foram realizados estudos comparativos dos anos de 1990 e 2015 , dentro dos limites geográficos apresentados. Os resultados evidenciaram vegetação densa com aumento de 7,34 km2 de cobertura vegetal e a semidensa de $8,85 \mathrm{~km} 2$, já a vegetação rala obteve um aumento significativo de $61,89 \mathrm{~km} 2$, no intervalo estudado de 25 anos. A vegetação semidensa rala teve uma diminuição de $60,73 \mathrm{~km} 2$ e a classe solo exposto houve redução significativa de $29,3 \mathrm{~km} 2$

Palavras-chave: Cobertura vegetal; Degradação dos solos; Risco.

\section{Vegetation cover classes in the municipality of Taperoá, Paraíba}

The municipality of Taperoá is located in the central region of the State of Paraiba, Mesoregion Borborema and Microregion of Western Cariri. The municipality is included in the geographic area of coverage of the semiarid region of Brazil, having as criteria the rainfall index, the aridity index and the risk of drought. This research is centered on the study of environmental degradation in the municipality of Taperoá - Paraiba, taking into account the geographic limits around the subbasin of the river, in the north, Areia de Baraúna, Salgadinho and Assunção, in the east, Santo André and São José dos Cordeiros, to the south, São José dos Cordeiros and Livramento, and to the west, Cacimbas and Passagem. Resources available through geoprocessing techniques were used. The general objective of the research is to analyze the levels of degradation from a space-time study of vegetation cover, land degradation, in addition to the region's vulnerabilities, which are social, economic, technological, environmental and susceptibility to droughts. To meet these objectives, comparative studies were carried out for the years 1990 and 2015, within the geographic limits presented. The results showed dense vegetation with an increase of $7.34 \mathrm{~km} 2$ of vegetation cover and the semi-dense one of $8.85 \mathrm{~km} 2$, while the thin vegetation had a significant increase of $61.89 \mathrm{~km} 2$, in the studied interval of 25 years. The thin semi-dense vegetation had a decrease of $60.73 \mathrm{~km} 2$ and the exposed soil class there was a significant reduction of $29.3 \mathrm{~km} 2$.

Keywords: Vegetal cover; Soil degradation; Risk.

Topic: Ciências do Solo

Reviewed anonymously in the process of blind peer.
Received: 03/04/2021

Approved: 26/04/2021
Júlia Soares Pereira (D)

Universidade Federal de Campina Grande, Brasil

http://lattes.cnpq.br/8908354485683197

http://orcid.org/0000-0002-6495-1169

julia_eng@hotmail.com

João Miguel de Moraes Neto ic

Universidade Federal de Campina Grande, Brasil

http://lattes.cnpq.br/3720844263112296

http://orcid.org/0000-0001-7672-5540

moraes@deag.ufcg.edu.br

\section{Viviane Farias Silva (iD)}

Universidade Federal de Campina Grande, Brasil

http://lattes.cnpq.br/5011520274887172

http://orcid.org/0000-0002-5891-0328

flordeformosur@hotmail.com

\author{
Kalyne Sonale Arruda de Brito (iD \\ Universidade Federal do Amapá, Brasil \\ http://lattes.cnpq.br/4329763474442768 \\ http://orcid.org/0000-0001-9560-1164 \\ line.brito@hotmail.com \\ Wanessa Alves Martins (iD \\ Universidade Federal de Campina Grande, Brasil \\ http://lattes.cnpq.br/4679230808516355 \\ http://orcid.org/0000-0002-2108-2530 \\ wanessamartins.eng@gmail.com
}

\section{Referencing this:}

PEREIRA, J. S.; MORAES NETO, J. M.; SILVA, V. F.; BRITO, K. S. A.; MARTINS, W. A.. Classes de cobertura vegetal no município de Taperoá, Paraíba. Revista Ibero Americana de Ciências Ambientais, v.12, n.4, p.1-7, 2021. DOI: http://doi.org/10.6008/CBPC21796858.2021 .004 .0001 


\section{INTRODUÇÃO}

O Nordeste do Brasil possui uma área de 393.897 km² enquadrada no nível de degradação ambiental moderado, $81.870 \mathrm{~km}^{2}$ em nível grave e $98.595 \mathrm{~km}^{2}$ em nível muito grave (BRASIL, 2010). Marengo et al. (2011) afirmam que com o início da agricultura que foi expandindo para a região semiárida, grande parte da área era ocupada por enormes fazendas de criação de gado, com uso de pasto nativo, a caatinga com pequenos agricultores com agricultura de subsistência, considerados extremamente vulneráveis as condições ambientais.

No domínio do semiárido, bioma caatinga, é caracterizado baixa pluviometria influenciando o curso dos rios, que secam em determinadas épocas, diminuindo a disponibilidade de água para plantas, animais e para os homens, aumentando a aridez do ambiente. O clima é então um fator determinante na caatinga, definindo a paisagem e os hábitos dos moradores deste bioma. Nesse contexto Chaves et al. (2013), relatam que estudos da vegetação e uso da terra vêm sendo desenvolvidos, com o objetivo de obter informações a partir de imagens de satélite e de outros produtos do sensoriamento remoto, em busca de facilitar a análise e a interpretação dos dados de superfície, para posterior estudo e avaliação buscando melhor aplicação na gestão do município.

A degradação está intimamente ligada à dinâmica das vulnerabilidades verificadas na região, sendo que a pobreza e a vulnerabilidade são condições que se reforçam mutuamente, seguido da deficiência nas políticas públicas, as condições climáticas desfavoráveis e solos de reduzida aptidão agrícola, principalmente quando estes recursos naturais são explorados por métodos insustentáveis do ponto de vista da sua preservação.

Estudos da vegetação e uso da terra vêm sendo pontos de pesquisa, com o objetivo de obter informações a partir de imagens de satélite e de outros produtos do sensoriamento remoto, em busca de facilitar a análise e a interpretação dos dados da superfície terrestre, pois índices de vegetação ressaltam o comportamento espectral de alvos de interesse de diversos ambientes, possibilitando distinguir alterações ao longo de décadas de degradação tanto antrópica, quanto natural. Florenzano (2011), relata que no cenário em que à interferência das ações antrópicas acabam por comprometer a preservação da vegetação, as ferramentas geotecnológicas de monitoramento através de imagens de Sensores Remotos podem ser amplamente utilizadas na análise da degradação vegetal.

Nesse contexto, a realização de pesquisas cientificas sobre a degradação ambiental, sua destruição ou regeneração, associado a vulnerabilidades da população, com o uso de geotecnologias que proporcionam verificar o uso do solo e aumento ou redução dos impactos ambientais em uma área, são fundamentais para a gestão dos recursos naturais e identificação dos fatores que causam a degradação ambiental, bem como para a tomada de decisão das políticas públicas na busca da sustentabilidade ambiental para a preservação do meio ambiente. Assim foi realizado a dinâmica da degradação ambiental no município Taperoá - PB utilizando as imagens do satélite Landsat 5 e 8 referentes ao período de 1990 e 2015. 


\section{MATERIAIS E MÉTODOS}

As imagens utilizadas neste trabalho foram adquiridas a partir do Catálogo de Imagens do Instituto Nacional de Pesquisas Espaciais (INPE), disponíveis de forma gratuita no site da instituição. O critério de seleção das imagens baseou-se principalmente na quantidade e distribuição de nuvens da área de estudo, obtidas a partir do satélite TM/Landsat - 5, com data de passagem 14/03/1990, e OLI/Landsat - 8, com data de passagem 06/05/2015, referentes a órbita 215 e ponto 65.

As técnicas de processamento digital de imagens foram divididas em 3 etapas: Pré Processamento de imagens: é o conjunto de processamentos por onde passa as imagens, visando minimizar, ao máximo, suas distorções. Estas distorções podem ser classificadas em radiométricas e geométricas. As distorções radiométricas alteram os níveis de cinza de cada elemento da imagem. Já as distorções geométricas alteram a distribuição espacial dos elementos de imagem, afetando escala, afinidade, orientação, entre outras; Realce de imagens: está técnica tem por objetivo modificar, através de funções matemáticas os níveis de cinza ou os outros valores digitais de uma imagem, de modo a destacar certas informações espectrais, melhorando a sua qualidade visual e facilitando a análise posterior pelo fotointérprete; Análise de imagens: está relacionada com a extração de informação de imagens. Inclui a segmentação e classificação de imagens. A segmentação tem por objetivo fragmentar uma região em unidades homogêneas, considerando algumas de suas características intrínsecas, como por exemplo, o nível de cinza dos pixels, textura e contraste. Já a classificação de imagens visa a categorização da cobertura da terra, distinguindo as composições de diferentes materiais superficiais, sendo uma segmentação específica usando técnicas de reconhecimento de padrões.

Os mapas finais das classes de vegetação e dos níveis de degradação das terrasforam criados no módulo SCARTA do software usado, SPRING.

\section{RESULTADOS E DISCUSSÃO}

A análise de cobertura vegetal de uma região através de imagens de satélites, de acordo com Ballén et al. (2016) podem gerar uma base para identificar as condições de uso do solo, como um parâmetro de qualidade ambiental, com dados fundamentais para estabelecer tipos de degradação, recuperação, agricultura, entre outros aspectos. A identificação de áreas com solo exposto, cobertura vegetal, área desmatada, possibilita a classificação e analisar os usos do solo e verificar os pontos graves para planejamento de recuperação ambiental (LIMA et al., 2013).

Em relação a classe de cobertura vegetal, em 1990 e 2015, observada na tabela 1, a cobertura vegetal pode ser classificada como densa, semidensa, semidensa rala, rala, rala mais solo exposto e solo exposto. A vegetação rala e solo exposto são identificados em alguns locais com áreas expressivas e preocupantes. Essas classes foram adaptadas por Barbosa et al. (2005), para o semiárido do Brasil, em várias pesquisas em sub bacias hidrográficas do Nordeste. 
Tabela 1: Quantificação de classes de cobertura vegetal nos anos de 1990 e 2015 no município de Taperoá/PB/Brasil.

\begin{tabular}{lllll}
\hline Cobertura Vegetal & $\mathbf{1 9 9 0}$ & \multicolumn{2}{l}{$\mathbf{2 0 1 5}$} \\
\hline Densa & Área $\left(\mathrm{km}^{2}\right)$ & $\%$ & Área $\left(\mathrm{km}^{2}\right)$ & $\%$ \\
\hline Semidensa & 8,29 & 1,25 & 15,63 & 2,36 \\
\hline Semidensa rala & 13,88 & 2,09 & 22,73 & 3,43 \\
\hline Rala & 140,83 & 21,25 & 80,1 & 12,1 \\
\hline Rala + solo exposto & 159,31 & 24,03 & 221,20 & 33,37 \\
\hline Solo exposto & 228,53 & 34,48 & 245,35 & 37,01 \\
\hline Água (Corpos d'água) & 107,54 & 16,23 & 78,25 & 11,8 \\
\hline Total & 4,35 & 0,66 & 0,0 & 0,0 \\
\hline
\end{tabular}

Ao comparar os anos de 1990 e 2015 (Figuras 1 e 2), observa-se que a vegetação densa teve um aumento de $7,34 \mathrm{~km}^{2}$ de cobertura vegetal e a semidensa de $8,85 \mathrm{~km}^{2}$, já a vegetação rala obteve um aumento significativo de $61,89 \mathrm{~km}^{2}$, no intervalo estudado de 25 anos. A vegetação semidensa rala teve uma diminuição de $60,73 \mathrm{~km}^{2}$, a classe solo exposta houve redução significativa de $29,3 \mathrm{~km}^{2}$. O que pode ser justificado com o aumento da vegetação densa pela redução do desmatamento para uso da madeira, área de agricultura e pecuária, ocasionando também aumento da vegetação rala. A prática da agricultura de plantas forrageiras justifica a redução do solo exposto, bem como as precipitações em curto espaço de tempo na época da imagem coletada.

Nascimento (2015) analisando um intervalo de 15 anos em área da caatinga, constataram que houve mudanças no ambiente analisado, com acréscimos na caatinga do tipo Arbustiva Aberta e Semiaberta, elevação dos solos expostos e atenuação caatinga do tipo Arbustivo-arbórea, relacionando as áreas de solo exposto e vegetação rala a questão de aumento na exploração dos recursos naturais com a pecuária. Silva e Almeida (2015) obtiveram resultados semelhantes ao estudarem imagens no intervalo de 1988 e 1995, com diminuição em área de vegetação densa e observaram que a vegetação nativa foi substituída por solo exposto.

Em visita in loco, Figura 3, foi constatado que em 2016 a área estudada tem desmatamento com extensões de manchas de solo exposto que se mostraram presentes em toda área, além da presente pecuária extensiva, como caprinos e bovinos, verificando que a vegetação rala+ solo exposto nesta imagem.

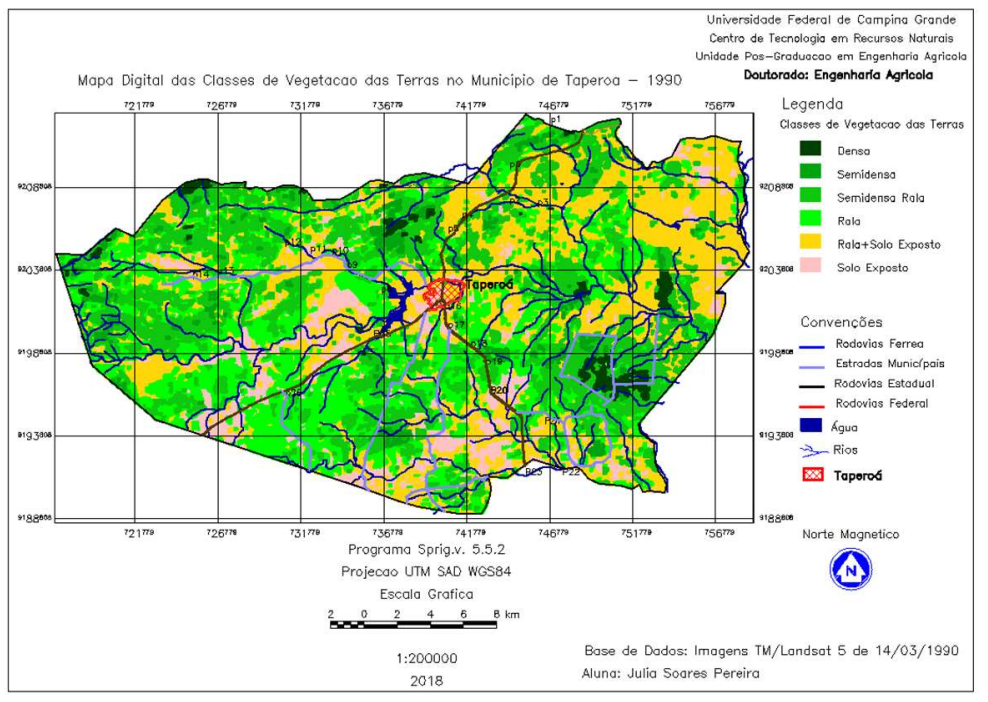

Figura 1: Classes de cobertura vegetal do município de Taperoá/PB/Brasil, ano 1990. 


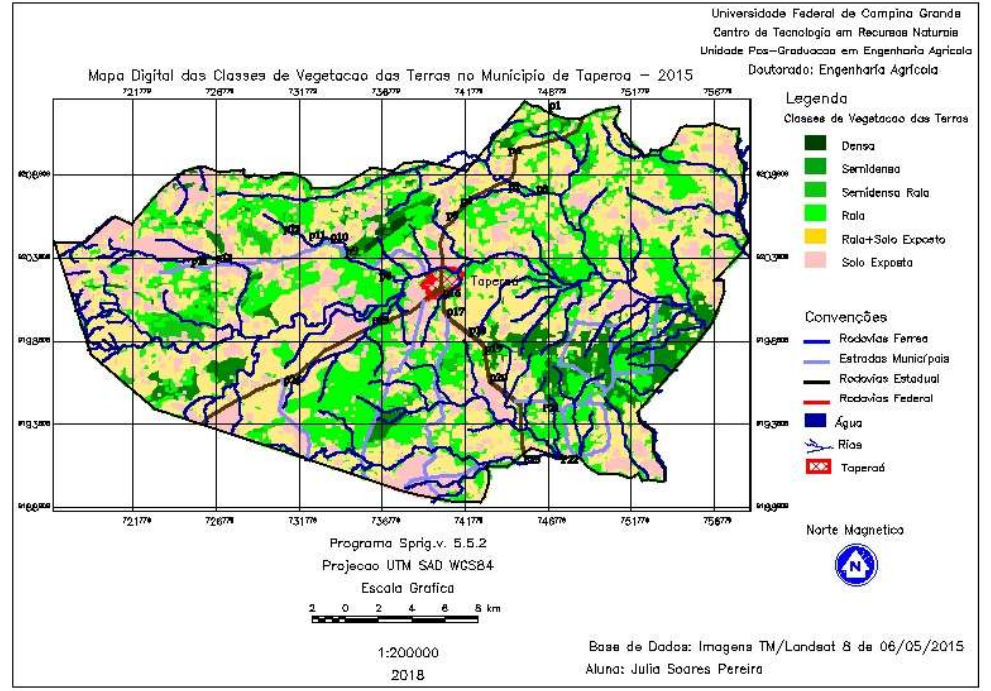

Figura 2: Classes de cobertura vegetal do município de Taperoá/PB/Brasil, ano 2015.

Resultados divergentes foram obtidos por Gonçalves et al. (2015) analisando a degradação ambiental de um município paraibano de Soledade, onde verificaram que em 1996 no mapa de vegetação, foram identificados que a vegetação densa com 4,99\% da área total e 2,48\% a classe solo exposta. Observa-se que esta área analisada por estes autores possui maior área coberta por vegetação, quando comparado com os dados obtidos nesta pesquisa.

Corroborando com esta pesquisa, Nascimento et al. (2014) analisando a degradação da Caatinga na sub-bacia do Alto Paraíba, destacam que em 1989 foi detectado alguns pontos com solo exposto, e maior concentração de caatinga semiaberta com 43,5\%. Souza et al. (2011) analisando o município de São Domingos do Cariri-PB, descrevem que em 1989 havia aproximadamente 69\% de área desertificada e em 2005 este índice teve elevação de 10\% da área total em 16 anos.

Em vários pontos observados em campo foi possível detectar diversas áreas em abandono, colaborando para regeneração natural da área (Figura 3).

A vegetação da caatinga possui mecanismos de defesa para as épocas de secas, com perdas de folhas e tempos de hibernação até o retorno das chuvas, em que a vegetação reaparece e continua seu ciclo vegetativo as vezes em curto prazo.

Estes mecanismos de adaptação e defesa para continuidade vegetativa, é pesquisada para adaptar culturas rentáveis para o clima semiárido, atualmente existe o arroz de sequeiro que antes apenas era cultivado em áreas alagadas, observando assim a magnitude da relevância da vegetação para desenvolvimento de pesquisas e da manutenção dos ecossistemas. A diminuição da vegetação, inclui perda de espécies de flora da caatinga, espécies de animais que também são espécies endêmicas do semiárido. Como afirmam Silva e Almeida (2015) a perda de folhas em épocas de escassez hídrica interfere na resposta espectral do solo em áreas com cobertura vegetal.

Na Figura 4, observou-se que a área está cercada para utilização da pecuária extensiva, com solo exposto e pedregoso, com indício de erosão laminar e em alguns locais erosão por sulcos, com perdas de solo, nutrientes, compactando o solo com a presença de animais, impactando fortemente o ambiente.

Nas regiões semiáridas, a vulnerabilidade das populações às variações climáticas constitui um grave 
problema. Sendo assim, incertezas geradas pelo aquecimento global reforçam a urgência quanto a necessidade de buscar formas de enfrentar a variabilidade climática atual, através do fortalecimento da resiliência e da redução da vulnerabilidade (RIBOT et al., 2005).

Wehbe et al. (2005) explicam que se uma determinada população agrícola é vulnerável a riscos climáticos não consegue lidar com eventos adversos, nem dispõe de mecanismos para isso - e o resultado pode ser uma situação de vulnerabilidade que compromete sua base de recursos e impede a sustentabilidade a médio e longo prazo.

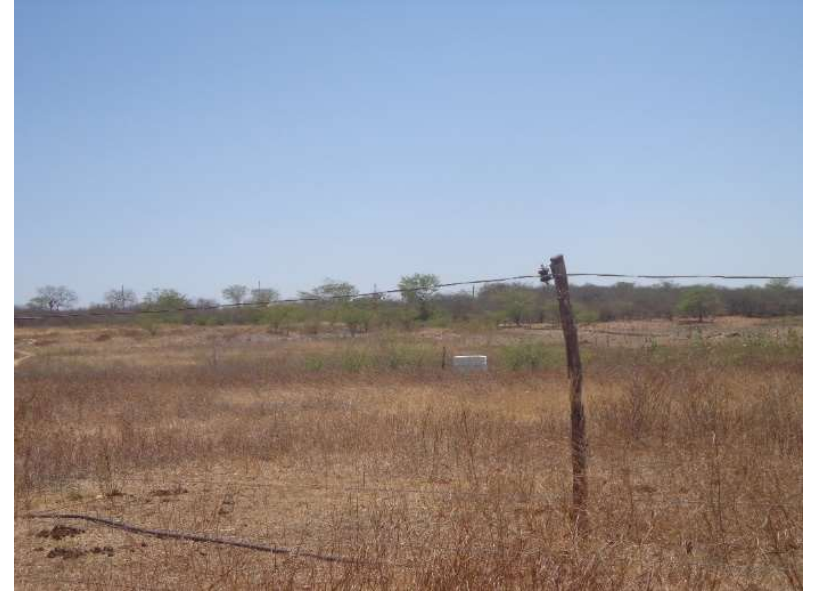

Figura 3: Área do município de Taperoá/PB/Brasil. Apresenta abandono das terras, permitindo regeneração da vegetação. Fonte: Pereira (2016).

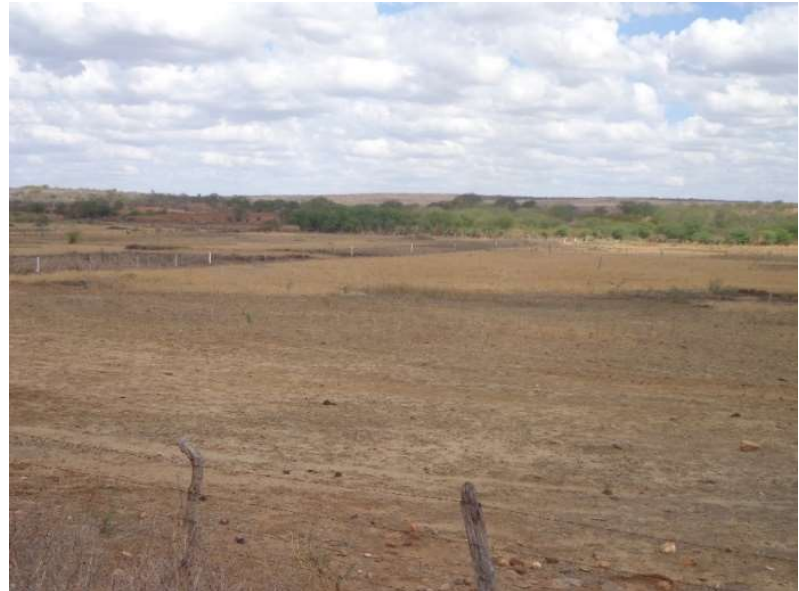

Figura 4: Área do município de Taperoá/PB/Brasil. Sistema de preparação do solo para pecuária extensiva. Fonte: Pereira (2016).

Os impactos ambientais ocasionados na caatinga, conforme Nascimento (2015) são resultados da utilização inadequada dos recursos naturais da caatinga, com substituição de mata nativa por culturas sazonais, sem manejo adequado do solo, nem reposição correta dos nutrientes, com perda da vegetação e nenhuma iniciativa de recuperação da mata, com perdas de espécies que não há em nenhum outro bioma.

Freire et al. (2017) constataram que analisando imagens de 1989 e 2003, houve elevação de solo exposto, redução de caatinga arbórea, arbustiva e elevação de áreas com ação antrópica. Relatam ainda que na análise da caatinga arbustiva pode ter ocorrido uma justaposição com os pastos e áreas de cultivo, pelas respostas espectrais serem similares.

\section{CONCLUSÕES}

A vegetação densa teve um aumento de $7,34 \mathrm{~km}^{2}$ de cobertura vegetal e a semidensa de $8,85 \mathrm{~km}^{2}$, já a vegetação rala obteve um aumento significativo de $61,89 \mathrm{~km}^{2}$, no intervalo estudado de 25 anos. A vegetação semidensa rala teve uma diminuição de $60,73 \mathrm{~km}^{2}$, a classe solo exposta houve redução significativa de $29,3 \mathrm{~km}^{2}$.

Em toda a área estudada e pelos relatos da população em mais de 10 anos sem produtividade, muitas áreas foram abandonadas, dando prioridade a agricultura de subsistência, o que mostra o aumento da vegetação semidensa. Já a redução da vegetação que apresenta densidade e o solo mais exposto foram características da exploração da pecuária extensiva, desmatamento, implantação de loteamentos da 
construção civil e o aumento da densidade demográfica. Essas atividades provocam perdas de biodiversidade, desencadeando processos erosivos e provocando assoreamento dos açudes.

As atividades antrópicas como: utilização inadequada das terras agrícolas, práticas deficientes no manejo de solos e água, desmatamento, remoção da vegetação natural, pastoreio excessivo, rotação incorreta de culturas e práticas não conservacionistas contribuíram diretamente na degradação.

\section{REFERÊNCIAS}

BARBOSA, E. I.; NASCIMENTO, S. R.; PORDEUS, R. B.. Percepções da caatinga, um bioma único e exclusivo do semiárido brasileiro. In: WORKSHOP INTERNACIONAL SOBRE ÁGUA NO SEMIÁRIDO BRASILEIRO CAMPINA GRANDE - PB, 1. Anais. 2005.

BALLÉN, L. A. C.; SOUZA, B. I.; LIMA, E. R. V.. Análisis espaciotemporal de la cobertura vegetal em el área de protección ambiental del cariri, Paraíba, Brasil. Boletim Goiano de Geografia, v.36, n.3, p.555-571, 2016.

BRASIL. Ministério do Meio Ambiente. Monitoramento dos biomas brasileiros por satélite acordo de cooperação técnica MMA/IBAMA. Monitoramento do Bioma Caatinga 2002 a 2008. Brasília: Centro de Sensoriamento Remoto CSR/IBAMA, 2010.

CHAVES, I. B.; FRANCISCO, P. R. M.; LIMA, E. R. V.; SILVA, B. B.; BRANDÃO, Z. N.; CHAVES, L. H. G.. Índices espectrais, diagnóstico da vegetação e degradação da caatinga na Bacia do Rio Taperoá-PB. In: SILVA, B. B.. Aplicações brasileiras de geoprocessamento e sensoriamento remoto. Campina Grande: EDUFCG, 2013. p.23-47.

FREIRE, N. C. F.; PACHECO, A. P.. Uma abordagem geoespacial e espectro-temporal da degradação ambiental no Bioma Caatinga na Região de Xingó, Brasil. Revista Ciência \& Trópico, v.14, n.2, p.97-128, 2017.

FLORENZANO, T. G.. Imagens de satélite para estudos ambientais. São Paulo: Oficina de Texto, 2011.
GONÇALVES, J. L. G.; FRANCISCO, P. R. M.; MORAES NETO, J. M.. Análise da degradação ambiental do município de Soledade utilizando índice de vegetação. In: CONGRESSO TÉCNICO CIENTIFICO DA ENGENHARIA E DA AGRONOMIA, CEARÁ. Anais. 2015.

MARENGO, J. A.; ALVES, L. M.; BESERRA, E. A.; LACERDA, F. F.. Variabilidade e mudanças climáticas no semiárido brasileiro. In: RECURSOS HÍDRICOS EM REGIÕES ÁRIDAS E SEMIÁRIDAS. Anais. 2011. p.383-422.

NASCIMENTO, F. C. A.; ARAÚJO, F. R. C. D.. Estudo comparativo entre o IVDN e a precipitação na região oeste potiguar. Revista Verde de Agroecologia e

Desenvolvimento Sustentável, v.9, p.269-274, 2014.

NASCIMENTO, F. R.. Bacias hidrográficas intermitentes sazonais e potencialidades hidroambientais no nordeste setentrional brasileiro. Rio de Janeiro: Universidade Federal Fluminense, 2015.

RIBOT, J. C.; OYONO, P. R.. The politics of decentralization. In: WISNER, B.; TOULMIN, C.; CHITIGA, R.. Towards A New Map of Africa. Earthscan, 2005.

WEHBE, M.; SEILER, R.; VINOCUR, M. G.; SANTOS, C.. Social Methods for Assessing Agricultural Producers: Vulnerability to Climate Variability and Change Based on the Notion of Sustainability. AIACC Working Paper n. 19, 2005.

A CBPC - Companhia Brasileira de Produção Científica (CNPJ: 11.221.422/0001-03) detém os direitos materiais desta publicação. Os direitos referem-se à publicação do trabalho em qualquer parte do mundo, incluindo os direitos às renovaç̃os, expansões e disseminacões da contribuicão, bem como outros direitos subsidiários. Todos os trabalhos publicados eletronicamente poderão posteriormente ser publicados em coletâneas impressas sob coordenação da Sustenere Publishing, da Companhia Brasileira de Produção Científica e seus parceiros autorizados. Os (as) autores (as) preservam os direitos autorais, mas não têm permissão para a publicação da contribuição em outro meio, impresso ou digital, em português ou em tradução. 